perceptive, cognitive, and affective deficits found with this disorder.

Macrocephaly and autism. The prevalence of macrocephaly ( $>97$ th centile) in autism and other pervasive developmental disorders was studied in 41 autistic children and in 21 children with tuberous sclerosis. Macrocephaly was diagnosed in $12 \%$ of probands with autism and in $15 \%$ of their first-degree relatives. These were higher prevalence rates than in normal children and in the comparison group of probands with TS $(9.5 \%)$ and their first-degree relatives $(8.3 \%)$. Macrocephaly may be a familal risk factor in the pathogenesis of autism. (Fidler DJ, Bailey JN, Smalley SL. Dev Med Child Neurol Nov 2000;42:737-740).

Prognosis of autism and Asperger's syndrome. Children with Asperger's syndrome had better social skills and fewer autistic symptoms when studied at 2 year follow-up than children with autism. (Szatnari P, Bryson SE, Streiner DL et al. Am J Psychiatry Dec 2000;157:1980-1987).

\title{
VASCULAR MALFORMATIONS
}

\section{SURGICAL OUTCOME IN STURGE-WEBER SYNDROME}

The presurgical epilepsy profile, criteria for surgery, and postoperative outcome of epilepsy were assessed in 20 patients with Sturge-Weber syndrome (SWS) consecutively admitted to the Hopital des Enfants Malades in Paris and the Montreal Neurological Institute. One had a callosotomy, 5 a hemispherectomy, and 14 had cortical excision. Age at onset of seizures ranged from 2 months to 12 years, and age at operation was at 8 months to 34 years. Visually guided complete resection of the pial angioma and underlying cortex was of benefit in most patients. Thirteen of 20 in the total group and all 5 patients with hemispherectomy became seizure-free. None showed worsening of cognitive impairment. (Arzimanaglou AA, Andermann F, Aicardi J et al. Sturge-Weber syndrome. Indications and results of surgery in 20 patients. Neurology Nov (2 of 2);55:1472-1479). (Reprints: Dr Alexis Arzimanoglou, Epilepsy Program, Service de Neurologie Pediatrique et des Maladies Metaboliques, Hopital Robert Debre, 48 Boulevard Serurier, 75019, Paris, France).

COMMENT. In patients with Sturge-Weber syndrome and drug-resistant epilepsy early surgery should be considered. Lesionectomy may be sufficient to control seizures when the pial angioma is unilateral, Hemispherectomy may be justified if the lesion is diffuse and causing a motor deficit and if symptoms are rapidly progressive.

Sturge-Weber syndrome with early onset seizures. The criteria for early epilepsy surgery were studied at the Child Developmental Center and Pediatric Neurology Unit, Tel Aviv Sourasky Medical Center, by a retrospective review of all Israeli infants with SWS and early onset seizures (before 18 months of age). Seizures presented at age 2 to 10 months. Five of 15 patients underwent surgery. Two undergoing surgery at 8 to 17 months have normal IQ at follow-up, whereas three operated at age 22 to 27 months have MR or borderline IQ At mean follow-up period of 15 years for all patients, 6 had normal IQ 4 had borderline IQ 3 mild mental retardation, and two had moderate mental retardation. Eight of 10 patients not operated still have seizures. Cognitive impairment was significantly correlated with seizure intensity in the early period, but not with age of seizure onset or seizure recurrences. (Kramer U, Kahana E, Shorer Z, Ben-Zeev B. Dev Med Child Neurol Nov 2000;42:756-759). 